spondyloarthritis (axSpA) spectrum of patients i.e. including not only patients with AS but also those with non-radiographic axSpA.

Objectives: To estimate a robust mapping between ASDAS and EQ5D (3 level version) and to test its performance out of sample (external validation) in patients with axSpA.

Methods: Data from an electronic, prospective, nationwide Rheumatic Disease Portuguese Register (Reuma.pt) provided data pertaining to 1140 patients (5483 observations) with a confirmed diagnosis of axSpA was used to develop a model to predict EQ5D from the ASDAS score. We compared a range of different statistical models developed to deal with the complex distributional features of health utility data. A range of criteria examining model fit across the spectrum of disease severity were used to select preferred models. A smaller dataset for out of sample validation from the SPondyloArthritis Caught Early (SPACE) cohort was used, providing data from 317 patients (1225 observations) at five European centres.

Results: Characteristics of patients from the Reuma.pt and SPACE are presented in the table. There is a non-linear relationship between ASDAS and EQ5D. We found that a four component mixture model based on a bespoke distribution, with one component constrained to reflect the mass of observations at full health, was the best fitting of the ASDAS models estimated (figure). ASDAS squared and age squared featured as within component variables. The model demonstrated close fit to the observed data where ASDAS was less than 4 but diverged from the mean of the data where ASDAS was higher. There is a very limited data at this more severe level of disease activity. In the out of sample testing, the model continued to perform well overall and exhibited the same divergence from the observed data only where data was sparse.

Conclusion: There is a clear relationship between ASDAS and EQ5D that we were able to model reliably using bespoke mixture model based methods. There is more uncertainty regarding model fit at very high levels of disease activity owing to the relative paucity of data from patients in such disease activity state. Future analyses may wish to focus on these severely affected patients in order to improve the robustness of model estimates.

Table. Characteristics of patients from the Reuma.pt and SPACE datasets

\begin{tabular}{|c|c|c|c|c|c|c|c|c|c|c|}
\hline & \multicolumn{5}{|c|}{ REUMA $(n=1140)$} & \multicolumn{5}{|c|}{ SPACE $(n=317)$} \\
\hline & $\mathrm{N}$ & Mean & sd & $\min$ & $\max$ & $\mathrm{N}$ & mean & sd & $\min$ & $\max$ \\
\hline Age at visit (yrs) & 5483 & 46.58 & 11.99 & 17.70 & 82.70 & 1225 & 31.44 & 7.78 & 16.14 & 50.46 \\
\hline Number of visits & 5483 & 4.81 & 5.26 & 1.00 & 39.00 & 1225 & 4.05 & 1.60 & 1.00 & 8.00 \\
\hline ASDAS total score & 4886 & 2.02 & 0.97 & 0.60 & 6.30 & 1181 & 2.10 & 0.96 & 0.64 & 5.44 \\
\hline BASDAl total score & 5383 & 2.97 & 2.26 & 0.00 & 10.00 & 1211 & 3.27 & 2.20 & 0.00 & 9.80 \\
\hline BASFI total score & 5258 & 2.84 & 2.41 & 0.00 & 9.88 & 1205 & 1.92 & 2.09 & 0.00 & 9.30 \\
\hline EQ-5D-3L & 5483 & 0.70 & 0.26 & -0.59 & 1.00 & 1225 & 0.69 & 0.25 & -0.59 & 1.00 \\
\hline Proportion Male & 5483 & 0.56 & & & & 1225 & 0.50 & & & \\
\hline
\end{tabular}

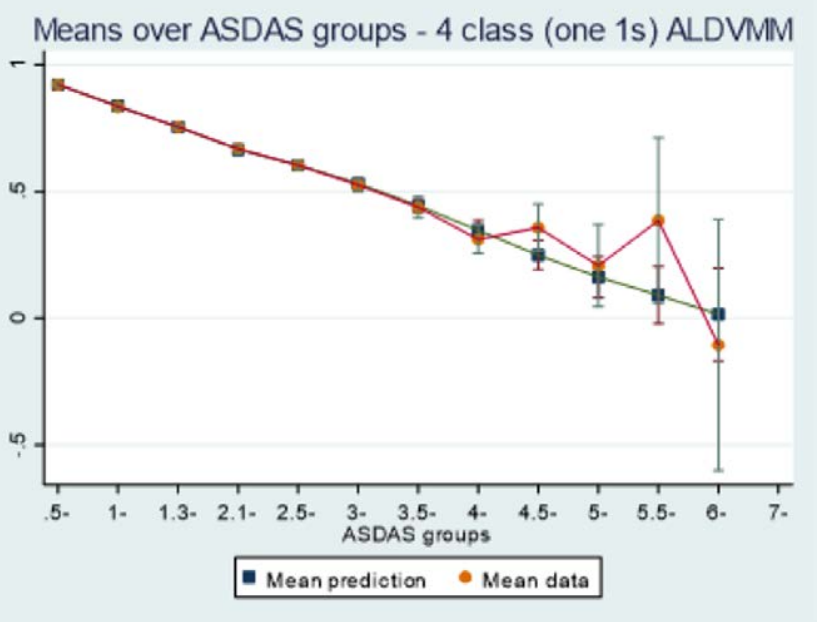

Figure. Mean observed versus fitted values for the preferred model mapping EQ5D-3L from ASDAS (Reuma.Pt dataset)

Acknowledgments: We would like to that all the contributors to the Reuma.Pt and SPACE datasets.

Disclosure of Interests: Monica Hernandez: None declared, Allan Wailoo: None declared, Georgios Chrysanthou: None declared, Pedro Carvalho: None declared, Désirée van der Heijde Consultant of: AbbVie, Amgen, Astellas, AstraZeneca, BMS, Boehringer Ingelheim, Celgene, Cyxone, Daiichi, Eisai, Eli-Lilly,
Galapagos, Gilead Sciences, Inc., Glaxo-Smith-Kline, Janssen, Merck, Novartis, Pfizer, Regeneron, Roche, Sanofi, Takeda, UCB Pharma; Director of Imaging Rheumatology BV, Maria Jose Santos Speakers bureau: Novartis and Pfizer Pedro M Machado Consultant of: PMM: Abbvie, Celgene, Janssen, Lilly, MSD, Novartis, Pfizer, Roche and UCB, Speakers bureau: PMM: Abbvie, BMS, Lilly, MSD, Novartis, Pfizer, Roche and UCB

DOI: 10.1136/annrheumdis-2020-eular.6196

\section{OP0079 \\ PRELIMINARY DEFINITION OF A POSITIVE MRI FOR STRUCTURAL LESIONS IN THE SACROILIAC JOINTS IN AXIAL SPONDYLOARTHRITIS}

W. P. Maksymowych ${ }^{1,2}$, X. Baraliakos ${ }^{3}$, U. Weber ${ }^{4}$, P. M. Machado ${ }^{5}$, S. Juhl Pedersen $^{6}$, J. Sieper ${ }^{7}$, S. Wichuk ${ }^{1}$, D. Poddubnyy ${ }^{7}$, M. Rudwaleit ${ }^{8}$, D. Van der Heijde $^{9}$, R. B. M. Landewé ${ }^{10}$, J. Paschke ${ }^{2}$, R. G. Lambert ${ }^{1}$, M. Ǿstergaard ${ }^{6}$. ${ }^{1}$ University of Alberta, Edmonton, Canada; ${ }^{2}$ CARE Arthritis, Edmonton, Canada; ${ }^{3}$ Rheumazentrum Ruhrgebiet, Herne, Germany; ${ }^{4}$ University of Southern Denmark, Sønderborg, Denmark; ${ }^{5}$ University College London, London, United Kingdom; ${ }^{6}$ Copenhagen University, København, Denmark; ${ }^{7}$ Charité - Universitätsmedizin Berlin, Berlin, Germany; ${ }^{8}$ Klinikum Bielefeld, Bielefeld Germany; ${ }^{9}$ Leiden University Medical Center (LUMC), Leiden, Netherlands; ${ }^{10}$ University of Amsterdam, Amsterdam, Netherlands

Background: There is lack of international consensus as to what defines a structural lesion on MRI of the sacroiliac joints (SIJ) typical of axial spondyloarthritis (axSpA). The ASAS MRI group has generated updated consensus lesion definitions that describe each of the MRI lesions in the SIJ ${ }^{1}$. These definitions have been evaluated by 7 readers from the ASAS-MRI group on MRI images from the ASAS Classification Cohort.

Objectives: We aimed to identify quantitative cut-offs based on numbers of slices and SIJ quadrants that define a positive MRI for structural lesions typical of $\operatorname{axSpA}$, the gold standard being majority central reader decision as to the presence of a structural lesion typical of axSpA with high confidence.

Methods: MRI structural lesions meeting ASAS definitions were recorded in an eCRF that comprises global assessment (structural lesion typical of axSpA present/absent and degree of confidence ( -4 (absent) to +4 (present)), and detailed scoring of lesions per SIJ quadrant. Detailed scoring was based only on assessment of DICOM images ( $n=148)$. We calculated sensitivity and specificity for numbers of SIJ quadrants and consecutive slices with erosion, sclerosis, and fat lesions where a majority of readers $(\geq 4 / 7)$ agreed as to the presence of a structural lesion typical of axSpA with high confidence $(\geq+3)$. We tested candidate lesion definitions for predictive diagnostic utility in cases assessed after 4.4 years of follow up by the local rheumatologist.

Results: Structural lesions typical of axSpA were observed by majority read in $33(32.4 \%)$ of 102 cases diagnosed with axSpA, and $3(6.8 \%)$ of 44 cases without axSpA and 29 cases were assigned a high degree of confidence ( $\geq$ +3 ) by a majority of readers. Cut-offs achieving specificity of $95 \%$ were erosion in $\geq 2$ consecutive slices (sensitivity $83 \%$ ), erosion $\geq 3$ SIJ quadrants (sensitivity $90 \%$ ), and fat lesion ( $\geq 1 \mathrm{~cm}$ horizontal depth) in $\geq 1$ SIJ quadrant (sensitivity $59 \%$ ) (Table). These had very high positive predictive values (>95\%) for diagnosis of axSpA in cases diagnosed by the rheumatologist after 4.4 years follow up.

Conclusion: ASAS-defined erosion in $\geq 2$ consecutive slices or in $\geq 3$ SIJ quadrants and ASAS-defined fat lesion with depth $>1 \mathrm{~cm}$ in $\geq 1$ SIJ quadrant are high priority candidates for defining an MRI structural lesion typical of axSpA. This will require similar assessment in additional axSpA cohorts.

References:

[1] Maksymowych et al. Ann Rheum Dis 2019; 78:1550-8.

Table 1. Majority readers agree structural lesion indicative of axSpA is present with confidence $\geq 3 / 4$ is the gold-standard external reference

\begin{tabular}{lcc}
\hline & Sensitivity & Specificity \\
\hline Erosion Score $\geq 1$ SIJ qdr & $93.1(77.2-99.2)$ & $80.6(72.4-87.3)$ \\
Erosion Score $\geq 2$ SIJ qdr & $93.1(77.2-99.2)$ & $90.8(84.1-95.3)$ \\
Erosion Score $\geq 3$ SIJ qdr & $89.7(72.6-97.8)$ & $95.8(90.5-98.6)$ \\
Erosion in 2 consecutive slices & $82.8(64.2-94.2)$ & $95.0(89.3-98.1)$ \\
Fat lesion $\geq 1$ SIJ qdr & $82.8(64.2-94.2)$ & $81.5(73.4-88.0)$ \\
Fat lesion $\geq 2$ SIJ qdr & $69.0(49.2-84.7)$ & $86.6(79.1-92.1)$ \\
Fat lesion $\geq 3$ SIJ qdr & $62.1(42.3-79.3)$ & $91.6(85.1-95.9)$ \\
Fat lesion in 2 consecutive slices & $55.2(35.7-73.6)$ & $93.3(87.2-97.1)$ \\
Fat lesion $(>1 \mathrm{~cm}$ depth) $\geq 1$ & $58.6(38.9-76.5)$ & $95.0(89.3-98.1)$ \\
Fat lesion $(>1 \mathrm{~cm}$ depth) $\geq 2$ & $55.2(35.7-73.6)$ & $95.8(90.5-98.6)$ \\
Fat lesion $(>1 \mathrm{~cm}$ depth) $\geq 3$ & $51.7(32.5-70.6)$ & $97.5(92.8-99.5)$ \\
Fat lesion $(>1 \mathrm{~cm}$ depth) in 2 consecutive slices & $48.3(29.4-67.5)$ & $97.5(92.8-99.5)$
\end{tabular}

Table. SIJ qdr: sacroiliac joint quadrant 
Disclosure of Interests: Walter P. Maksymowych Grant/research support from: AbbVie, Novartis, Pfizer, and UCB, Consultant of: AbbVie, Boehringer Ingelheim, Celgene, Eli Lilly, Galapagos, Janssen, Novartis, Pfizer, and UCB, Employee of: Chief Medical Officer of CARE Arthritis Limited, Speakers bureau: AbbVie, Janssen, Novartis, Pfizer, and UCB, Xenofon Baraliakos: None declared, Ulrich Weber: None declared, Pedro M Machado Consultant of: PMM: Abbvie, Celgene, Janssen, Lilly, MSD, Novartis, Pfizer, Roche and UCB, Speakers bureau: PMM: Abbvie, BMS, Lilly, MSD, Novartis, Pfizer, Roche and UCB, Susanne Juhl Pedersen Grant/research support from: Novartis, Joachim Sieper Consultant of: AbbVie, Boehringer Ingelheim, Eli Lilly and Company, Janssen, Merck, Novartis, Pfizer, Roche, and UCB Pharma, Speakers bureau: AbbVie, Boehringer Ingelheim, Eli Lilly and Company, Janssen, Merck, Novartis, Pfizer, Roche, and UCB Pharma, Stephanie Wichuk: None declared, Denis Poddubnyy Grant/research support from: AbbVie, MSD, Novartis, and Pfizer, Consultant of: AbbVie, Bristol-Myers Squibb, Eli Lilly, MSD, Novartis, Pfizer, Roche, UCB, Speakers bureau: AbbVie, Bristol-Myers Squibb, Eli Lilly, MSD, Novartis, Pfizer, Roche, UCB, Martin Rudwaleit Consultant of: AbbVie, BMS, Celgene, Janssen, Eli Lilly, MSD, Novartis, Pfizer, Roche, UCB Pharma, Désirée van der Heijde Consultant of: AbbVie, Amgen, Astellas, AstraZeneca, BMS, Boehringer Ingelheim, Celgene, Cyxone, Daiichi, Eisai, Eli-Lilly, Galapagos, Gilead Sciences, Inc., Glaxo-Smith-Kline, Janssen, Merck, Novartis, Pfizer, Regeneron, Roche, Sanofi, Takeda, UCB Pharma; Director of Imaging Rheumatology BV, Robert B.M. Landewé Consultant of: AbbVie; AstraZeneca; Bristol-Myers Squibb; Eli Lilly \& Co.; Galapagos NV; Novartis; Pfizer; UCB Pharma, Joel Paschke: None declared, Robert G Lambert: None declared, Mikkel Ǿstergaard Grant/research support from: AbbVie, Bristol-Myers Squibb, Celgene, Merck, and Novartis, Consultant of: AbbVie, Bristol-Myers Squibb, Boehringer Ingelheim, Celgene, Eli Lilly, Hospira, Janssen, Merck, Novartis, Novo Nordisk, Orion, Pfizer, Regeneron, Roche, Sandoz, Sanofi, and UCB, Speakers bureau: AbbVie, Bristol-Myers Squibb, Boehringer Ingelheim, Celgene, Eli Lilly, Hospira, Janssen, Merck, Novartis, Novo Nordisk, Orion, Pfizer, Regeneron, Roche, Sandoz, Sanofi, and UCB

DOI: 10.1136/annrheumdis-2020-eular.6264

\section{\begin{tabular}{|l|l}
\hline OP0080 & CENTRAL SENSITIZATION AND ILLNESS
\end{tabular} PERCEPTIONS SHOULD BE TAKEN INTO ACCOUNT WHEN INTERPRETING DISEASE ACTIVITY IN PATIENTS WITH AXIAL SPONDYLOARTHRITIS}

S. Kieskamp ${ }^{1}$, D. Paap ${ }^{1,2}$, M. Carbo ${ }^{1}$, F. Wink ${ }^{3}$, R. Bos ${ }^{3}$, H. Bootsma ${ }^{1}$, S. Arends ${ }^{1,3}$, A. Spoorenberg ${ }^{1,3} .{ }^{1}$ University Medical Center Groningen, Rheumatology and Clinical Immunology, Groningen, Netherlands; ${ }^{2}$ University Medical Center Groningen, Rehabilitation Medicine, Groningen, Netherlands; ${ }^{3}$ Medical Center Leeuwarden, Rheumatology, Leeuwarden, Netherlands

Background: Up to $40 \%$ of ankylosing spondylitis patients report persistently high pain scores of $>4$ (scale of $0-10$ ) even after responding to long-term TNF-alpha blocking therapy.[1] In other rheumatic diseases, nociplastic pain (due to altered functioning of the nervous system leading to peripheral and central sensitization) is common.[2] In axial spondyloarthritis (axSpA), patient illness and pain perceptions were shown to influence disease outcome.[3] Therefore, we hypothesized that central sensitization and patients' illness perceptions are associated with persistently high disease activity in axSpA.

Objectives: To investigate to what extent central sensitization, pain catastrophizing and patients' perceptions play a role in axSpA and to explore associations with disease activity.

Methods: Between April and September 2019, consecutive outpatients from the Groningen Leeuwarden axSpA (GLAS) cohort,[4] an ongoing large prospective cohort, were included in this study. Besides the standardized assessments, patients filled out three additional questionnaires: Central Sensitization Inventory (CSI), Pain Catastrophizing Scale (PCS) and Revised IIIness Perception Questionnaire (IPQ-R). Univariable and multivariable linear regression analyses were used to investigate the association of CSI, PCS and each of the eight subscales of the IPQ-R, and disease activity assessments ASDAS-CRP, BASDAI, and CRP. We corrected for the following potential confounders: gender, symptom duration, BMI, educational level, smoking status and HLA-B27 status.

Results: Of 171 included patients, 58\% were male, $79 \%$ were HLA-B27 positive, median symptom duration was 21 (IQR 10-32), mean ASDAS-CRP 2.1 \pm 1.0, mean BASDAI $3.9 \pm 2.2$ and median CRP 2.9 (IQR 1.2-6.3). Mean CSI score was $37.8 \pm 14.1$ (scale of $0-100$ ), and $44 \%$ of patients scored $\geq 40$ on the CSI.[5] Median PCS score was 15 (IQR 7-22) (scale of 0-52), median IPQ-R illness identity subscore 3 (IQR 2-4) (scale of 0-14) and mean IPQ-R treatment control subscore $18.1 \pm 3.4$ (scale of $5-25$ ). In univariable regression analysis, CSI and PCS scores and IPQ-R subscores all showed significant associations with ASDAS-CRP, and all except the IPQ-R subscale personal control showed significant associations with BASDAI. Only IPQ-R treatment control was significantly associated with CRP. Central sensitization, two IPQ-R subscales (perceived treatment control and the number of symptoms patients attributed to their axSpA: illness identity) and BMI were independently associated with disease activity assessments BASDAI $\left(R^{2}=0.46\right)$ and ASDAS-CRP $\left(R^{2}=0.36\right)$ (Figure 1).

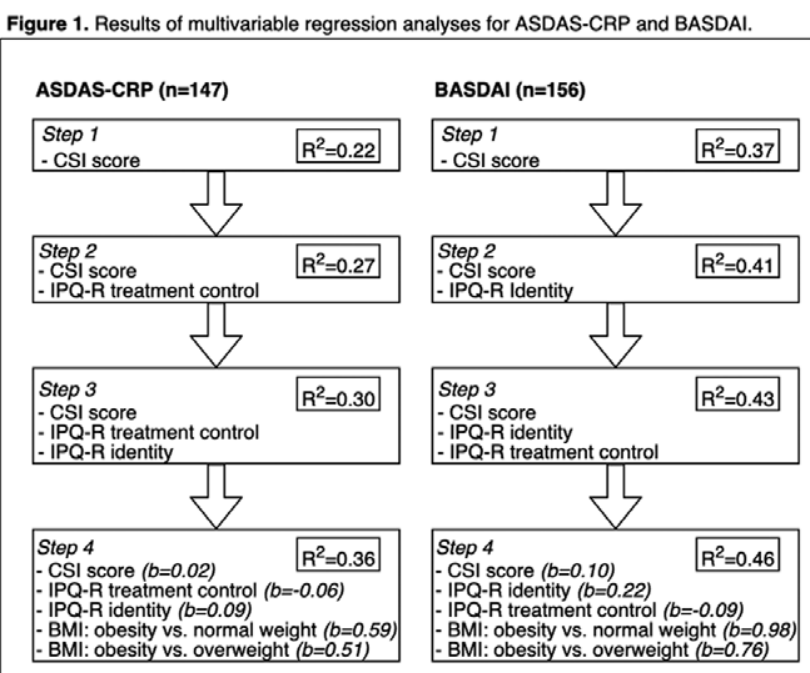

ASDAS-CRP: Ankylosing Spondylitis Disease Activity Score with C-reactive protein; BASDAI: Bath Ankylosing Spondylitis Disease Activity Score; CSI: Central Sensitization Inventory; IPQ-R: Revised IIIness Perception Questionnaire; BMI: Body Mass Index.

Conclusion: In this axSpA population with long-term disease, 44\% scored above the CSI cutoff point of 40 , indicating a high probability of central sensitization. CSI score, illness identity and treatment control were independently associated with disease activity assessments.

\section{References:}

[1] Arends S et al. Clin Exp Rheumatol 2017;35(1):61-8.

[2] Meeus M et al. Semin Arthritis Rheum 2012;41(4):556-67.

[3] Van Lunteren M et al. Arthritis Care Res (Hoboken) 2018;70(12):1829-39.

[4] Arends S et al. Arthritis Res Ther 2011;13(3):R94.

[5] Neblett R et al. J Pain 2013;14(5):438-45.

Disclosure of Interests: Stan Kieskamp: None declared, Davy Paap: None declared, Marlies Carbo: None declared, Freke Wink Consultant of: Abbvie, Janssen, Reinhard Bos: None declared, Hendrika Bootsma Grant/research support from: Unrestricted grants from Bristol-Myers Squibb and Roche, Consultant of: Consultant for Bristol-Myers Squibb, Roche, Novartis, Medimmune, Union Chimique Belge, Speakers bureau: Speaker for Bristol-Myers Squibb and Novartis. Suzanne Arends Grant/research support from: Grant/research support from Pfizer, Anneke Spoorenberg: None declared DOI: 10.1136/annrheumdis-2020-eular. 1684

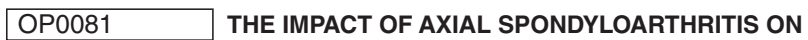 PATIENTS' SEXUAL LIFE: RESULTS FROM THE EUROPEAN MAP OF AXIAL SPONDYLOARTHRITIS (EMAS)}

M. Garrido-Cumbrera ${ }^{1,2}$, C. Bundy ${ }^{3}$, D. Poddubnyy ${ }^{4,5}$, S. Makri ${ }^{6}$,

R. Mahapatra ${ }^{7}$, S. Sanz-Gómez ${ }^{1}$, L. Christen ${ }^{8}$, C. J. Delgado-Domínguez ${ }^{1}$, V. Navarro-Compán ${ }^{9}$ on behalf of EMAS Working Group. ${ }^{1}$ Health \& Territory Research (HTR), Universidad de Sevilla, Sevilla, Spain; ${ }^{2}$ Spanish Federation of Spondyloarthritis Associations (CEADE), Madrid, Spain; ${ }^{3}$ Cardiff University, Cardiff, United Kingdom; ${ }^{4}$ Charité - Universitätsmedizin Berlin, Berlin, Germany; ${ }^{5}$ German Rheumatism Research Centre, Berlin, Germany; ${ }^{6}$ Cyprus League Against Rheumatism, Nicosia, Cyprus; ${ }^{7}$ Axial Spondyloarthritis International Federation (ASIF), London, United Kingdom; ${ }^{8}$ Novartis Pharma AG, Basel, Switzerland; ${ }^{9}$ University Hospital La Paz, IdiPAZ, Madrid, Spain

Background: Axial Spondyloarthritis (axSpA) involves a great degree of functional limitation in daily activities and psychological health, which can impact patients' sexual life.

Objectives: To study the determinants of reduced frequency of sexual activity and intimacy since disease onset in axSpA patients. 